\title{
Morfologia do pericárdio do sagui-de-tufo-preto (Callithrix penicillata)
}

\author{
Luana Célia Stunitz da Silva ${ }^{1 *}$ \\ Camila Ercolini Barroso ${ }^{1}$ \\ Pedro Primo Bombonato ${ }^{2}$ \\ ${ }^{1} \mathrm{PPG}$ em Anatomia dos Animais Domésticos e Silvestres \\ ${ }^{2}$ Departamento de Cirurgia, Faculdade de Medicina Veterinária e Zootecnia \\ Universidade de São Paulo, São Paulo/SP, Brasil \\ Avenida Prof. Dr. Orlando Marques de Paiva, CEP 05508-270, São Paulo - SP, Brasil \\ *Autor para correspondência \\ luanastunitz@usp.br
}

Submetido em 04/07/2011

Aceito para publicação em 29/09/2011

\section{Resumo}

Embora muitas das enfermidades que acometem os saguis já tenham sido descritas, ainda existe uma carência de informações de cunho anatômico deles. Nesse aspecto, objetivou-se descrever a morfologia histológica e ultraestrutural do pericárdio do sagui-de-tufo-preto (Callithrix penicillata) utilizando quatro espécimes adultos, procedentes de um criadouro de animais selvagens, que vieram a óbito por causas naturais. Inicialmente, realizou-se a dissecação para exposição e retirada do pericárdio em todos os primatas, o qual foi posteriormente remetido para processamento tanto para microscopia eletrônica de varredura como para microscopia óptica, com coloração de hematoxilina/eosina (HE) e tricrômio de Masson. Isso resultou na observação de uma camada única de células epiteliais, denominada de mesotélio, e a presença de prolongamentos celulares e poros. Pôde-se, então, concluir que o pericárdio do sagui-de-tufo-preto apresenta características microscópicas e ultraestruturais muito similares ao rato, camundongo e hamster dourado. Possui, entretanto, prolongamentos celulares ao invés de microvilosidades já descritas em outras espécies animais.

Palavras-chave: Anatomia veterinária, Coração, Primata, Sagui

\section{Abstract}

Morphology of pericardium of black-tufted-ear-marmoset (Callithrix penicillata). Although many of the diseases that affect the marmosets have already been described, there is a lack of anatomical information on them. In this regard, this study aimed to describe the histological and ultrastructural morphology of the pericardium of black-tufted-ear-marmoset (Callithrix penicillata) using four adult specimens from a breeding of wild animals that died from natural causes. Initially, the dissection for exposing and removing the pericardium was carried out in all the primates, which was afterwards sent for analysis both through scanning electronic microscopy and through light microscopy, stained with hematoxylin/eosin (HE) and Masson trichrome. This resulted in the observation of a single layer of epithelial cells, named mesothelium, and the presence of cellular extensions and pores. Thus, one can conclude that the pericardium of black-tufted-ear-marmoset has microscopic and ultrastructural characteristics very similar to those of rat, mouse, and golden hamster. It has, however, cellular extensions instead of microvilli previously described in other animal species.

Key words: Heart, Marmoset, Primate, Veterinary anatomy 


\section{Introdução}

Apesar de muitas das enfermidades que acometem os saguis já tenham sido descritas existe ainda uma carência de informações de cunho anatômico dos mesmos. Nesse aspecto cita-se o pericárdio, o qual é um envoltório fibroseroso fino que engloba o coração, situando-se no aspecto ventral do mediastino médio ao longo de uma quantidade variável de gordura (EVANS; LAHUNTA, 1994; KÖNIG; LIEBICH, 2007). O pericárdio é inervado pelos nervos vago, laringo recorrente e plexo esofageano. Inervação simpática é provida pelos gânglios estrelado, primeiro dorsal e plexos aórtico e diafragmático (KLUWER, 2003).

Tal estrutura é encontrada nos vertebrados desde os animais mais inferiores até os seres humanos e tem sido enfoque de estudo em uma grande variedade de espécies animais (KLUWER, 2003). Sendo formado por dois folhetos, em que o primeiro, mais externo, é denominado de folheto fibroso, o qual é inelástico formado por uma malha de fibras de colágenas entrecruzadas e se encontra recoberto externamente pela pleura mediastínica ou pleura pericárdica. O segundo folheto, mais interno, folheto seroso, é um saco fechado que recobre a maior parte do coração. Estando o mesmo formado pelas lâminas parietal e visceral. A lâmina parietal se encontra aderida à superfície interna do folheto fibroso e quando se aproxima da superfície do coração sofre uma reflexão e passa a revestir a superfície externa do mesmo e os vasos coronários, sendo então chamada de lâmina visceral ou epicárdio. Entre essas duas lâminas, existe um espaço denominado de cavidade pericárdica, que é preenchido pelo líquido pericárdico, permitindo assim uma maior liberdade de movimentos pelo coração. Nos cães observa-se uma quantidade aproximada de $0,29 \mathrm{ml} /$ $\mathrm{kg}$ de líquido, e no ser humano com peso corpóreo de $75 \mathrm{~kg}$ relata-se a existência de $30 \mathrm{~mL}$ de tal fluido (EVANS, 1993; EVANS; LAHUNTA, 1994; KLUWER, 2003; KÖNIG; LIEBICH, 2007; AKERS; DENBOW, 2008).

No pericárdio pode ser encontrado o ligamento esternopericárdico, que liga o osso esterno ao pericárdio fibroso, ou o ligamento frenicopericárdico que faz a conexão entre o diafragma ao pericárdio fibroso, variando conforme a espécie animal analisada (EVANS; LAHUNTA, 1994). Bem como também a presença constante de dois recessos os quais são revestidos pela lamina visceral. Ao nível da base do coração existe uma comunicação em forma de "U" entre o lado direito e esquerdo da cavidade pericárdica formando então o seio transverso do pericárdio ou sinus transversus pericardii. Este é delimitado anteriormente pela superfície posterior da aorta e pela artéria pulmonar, e posteriormente pela superficie anterior e pelo sulco interatrial. No caso do seio obliquo do pericárdio ou sinus obliquus pericardii este é uma invaginação formada pela reflexão das lâminas do pericárdio seroso, entre as grandes veias da base do coração estando localizado atrás do átrio esquerdo (EVANS, 1993; EVANS; LAHUNTA, 1994; AKHTER 2011).

O pericárdio é capaz de suportar pequenas distensões durante o ciclo cardíaco. Mas quando ocorre um acúmulo rápido de fluido dentro da cavidade pericárdica tem-se um aumento na pressão sobre o coração impossibilitando assim a função cardíaca. E em casos de hipertrofia cardíaca, por estreitamento físico durante um tempo prolongado, ocorre um aumento no tamanho do pericárdio (KÖNIG; LIEBICH, 2007). A inflamação do pericárdio, denominada pericardite, acarreta uma diminuição na produção do liquido pericárdico e a formação de uma membrana serosa áspera. Levando assim, a um som de abafamento na auscultação cardíaca. Em casos severos de inflamação ocorre um excesso de produção do líquido pericárdico, tendo por consequência a compressão do coração e diminuição da agilidade de bombeamento (AKERS; DENBOW, 2008).

Atualmente tem-se uma grande aplicabilidade do pericárdio na área da medicina e medicina veterinária, como por exemplo, o emprego desta estrutura para retalhos na restauração de defeitos no músculo diafragma (FILHO et al., 2003), como membrana biológica para o tratamento de feridas limpas e com pouca exsudação (BELLENZANI et al., 1998), dentre outros.

Tendo em vista o exposto e sabendo que o pericárdio possui grande interesse e necessidade de esclarecimentos a despeito de sua morfologia, bem como também o conhecimento acerca da nossa fauna é de fundamental relevância. $\mathrm{O}$ objetivo do estudo foi descrever através da microscopia óptica e da microscopia eletrônica de 
varredura os arranjos celulares do pericárdio do Saguide-tufo-preto (Callithrix penicillata).

\section{Material e Métodos}

Foram utilizados quatro saguis-de-tufo-preto (Callithrix penicillata) adultos, com idades entre seis e oito anos, procedentes de um criadouro de animais selvagens localizado em Atibaia-SP. Os animais vieram a óbito por causas naturais e foram encaminhados ao Laboratório de Anatomia dos Animais Domésticos e Silvestres da Universidade de São Paulo (USP) para estudos anatômicos. Os mesmos foram colocados em cubas, contendo solução de formaldeído $10 \%$, por no mínimo $72 \mathrm{~h}$ para a sua posterior dissecação. Inicialmente realizou-se uma incisão ventral na região do manúbrio do esterno até o processo xifóide para então o rebatimento da pele, fáscia subcutânea e músculos. Permitindo assim a retirada do osso esterno para a plena visualização do coração e do pericárdio. Posteriormente, foram coletadas amostras do pericárdio e acondicionadas em potes plásticos contendo solução de formaldeído $10 \%$.

Os fragmentos foram então desidratadas em uma série crescente de etanóis ( $60 \%$ a 100\%), diafanizadas em xilol, incluídos em parafina Histosec e obtidos cortes de $5 \mu \mathrm{m}$ de espessura em micrótomo, os quais foram corados por HE (Hematoxilina/Eosina) e Tricrômio de Masson, e fotodocumentados (Leica DM 2000). A nomenclatura utilizada foi baseada no International Commitee on Veterinary Gross Histological and Anatomical Nomenclature (1994).

Para os demais fragmentos do pericárdio foi efetuada fixação em glutaraldeído $2,5 \%$ por $72 \mathrm{~h}$ e pósfixadas em solução de tetróxido de Ósmio 1\% em PBS $0,1 \mathrm{M}$ por $2 \mathrm{~h}$. Posteriormente, as amostras foram lavadas por 45min em solução PBS 0,1M, e em água destilada por $20 \mathrm{~min}$. Ao final, o material foi desidratado em séries crescentes de alcoóis (50\% a 100\%) por 30min em cada série. Para que fossem então secas em aparelho de ponto crítico Balzers CPD 020 com uso de $\mathrm{CO}_{2}$ líquido, montados em bases metálicas de alumínio (stub) com cola de carbono e submetidas a um revestimento metálico ("sputting") com ouro.
Os fragmentos foram analisados e fotografados em microscópio eletrônico de varredura LEO 435VP (FMVZ-USP).

\section{Resultados}

A análise microscópica, tanto com a coloração de HE como pelo Tricrômio de Masson, permitiu a observação de uma monocamada de células epiteliais sob uma camada de tecido fibroelástico nos fragmentos de pericárdio coletados (Figuras 1A e 1B). E por meio da microscopia eletrônica de varredura pôde-se notar a presença de diversos prolongamentos celulares e de poros intercelulares (Figuras 1C e 1D).

\section{Discussão}

Como descrito por Groell (2005), o aspecto microscópico do pericárdio observado neste estudo foi o de uma camada única de células epiteliais, denominada de mesotélio, a qual estava repousando sobre uma camada de tecido fibroelástico (Figuras A e B). Segundo Spodick (1983), esta monocamada possui um número considerável de sobreposições e interdigitações, o que favorece mudanças na configuração da superfície pericárdica, mas mantendo ainda a estabilidade mecânica (SPODICK, 1983). Tais células mesoteliais secretam uma pequena quantidade de líquido seroso, o qual tem por função lubrificar o movimento do coração quando ocorre o batimento. Possuindo ainda a capacidade de alterar de forma e tamanho conforme o ciclo cardíaco, tendendo a uma posição perpendicular na sístole e oblíqua na diástole (SPODICK, 1983; GROELL, 2005). A anatomia do pericárdio inclui também a presença de células fibrosas, vasculares e elementos linfáticos (SPODICK, 1983).

A respeito do aspecto ultraestrutural do pericárdio, as células mesoteliais apresentam microvilosidades, com cerca de $3 \mu \mathrm{m} X 1 \mu \mathrm{m}$, as quais se projetam das lâminas visceral e parietal, e têm a função de auxiliar na distribuição do liquido pericárdico, o deslizamento e diminuição do atrito entre as duas superfícies das lâminas durante o ciclo cardíaco, aumentar a área de superfície e facilitar a troca de fluidos e íons (SPODICK, 1983; 
FIGURA 1: (A, B) Fotomicrografias histológicas do pericárdio do sagui-de-tufo-preto (Callithrix penicillata) evidenciando as células epiteliais denominadas de mesotélio (1) sobre a camada de tecido fibroelástico (2) (A - coloração de HE, 10X; B-coloração Tricrômio de Masson, 100X). (C, D) Ultraestrutura do pericárdio do sagui-de-tufo-preto (Callithrix penicillata) evidenciando os prolongamentos celulares $(*) \mathrm{e}$ os poros intercelulares (círculos pretos).
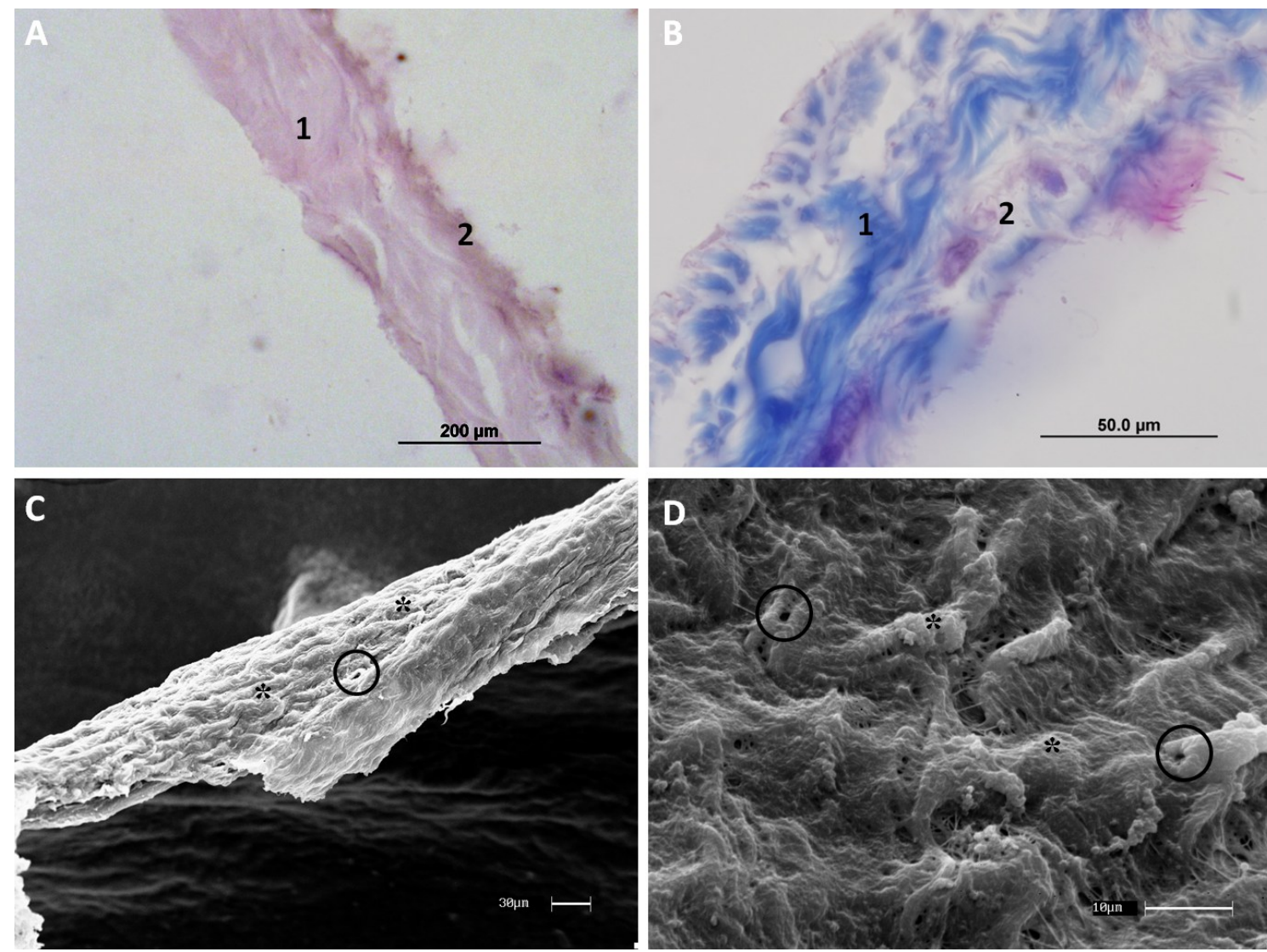

KLUWER, 2003). Apresentam também cílios únicos, os quais são maiores que as microvilosidades, mas em menor número. No caso das amostras analisadas para a espécie Callithrix penicillata não se observou a existência destas estruturas, mas sim a presença de prolongamentos celulares, os quais podem ter a mesma função que as microvilosidades (Figuras $1 \mathrm{C}$ e 1D). De acordo com KLUWER (2003) os microvilos e os cílios são capazes de permitir ao pericárdio se acomodar às mudanças de tamanho e formato no ciclo cardíaco.

Segundo Nakatani et al. (1988), no caso do pericárdio de alguns roedores observou-se a presença de diversos poros, assim como já descrito para o hamsterdourado, rato e camundongo, sendo mais numerosos no camudongo, os quais os possuíam com geralmente menos de $50 \mu \mathrm{m}$ de diâmetro. Estando os mesmos situados em uma malha formada por fibras colágenas onduladas grossas e fibras elásticas finas e retas. Fato este que vem de encontro com os achados deste estudo. Tais poros têm por função conectar diretamente a cavidade pleural e pericárdica e de forma indireta a cavidade pleural direita e esquerda (NAKATANI et al., 1988).

Com o material analisado e a técnica empregada pôde-se concluir que o pericárdio do sagui-de-tufopreto (Callithrix penicillata) possui características microscópicas e ultraestruturais muito similares ao rato, camundongo e hamster-dourado. Possuindo, entretanto prolongamentos celulares ao invés de microvilosidades já descritas para outras espécies animais. 


\section{Agradecimentos}

Ao criadouro comercial de animais selvagens, AJBSoares, pela disponibilidade e fornecimento dos animais analisados; à Médica Veterinária Marta Brito Guimarães e à técnica de laboratório de Microscopia Eletrônica de Varredura do Departamento de Cirurgia da FMVZ-USP, Rose Eli Grassi Rici.

\section{Referências}

AKERS, R. M.; DENBOW, D. M. Anatomy \& Physiology of domestic animals. Iowa: Blackwell Publishing, 2008. 612 p.

AKHTER, S. A. The heart and pericardium. Thoracic Surgery Clinics, Philadelphia, v. 21, p. 205-217, 2011.

BELLENZANI, M. C. R.; MATERA, J. M.; GIACÓIA, M. R. Homologous pericardium as a biological dressing for treatment of distal limb wound in horses- experimental study. Acta Cirúrgica Brasileira, São Paulo, v. 13, p. 238-242, 1998.

EVANS, H. E. Anatomy of the dog. Philadelphia: W.B. Saunders Company, 1993. $1113 \mathrm{p}$.
EVANS, H. E.; LAHUNTA, A. Guia para a dissecção do cão. Rio de Janeiro: Guanabara Koogan, 1994. 206 p.

FILHO, S. T. L.; BRONDANI, J. T.; GRAÇA, D. L.; SCHOSSLER, J. E. Restauração do diafragma de felino com enxerto autólogo de pericárdio. Acta Cirúrgica Brasileira, São Paulo, v. 18, n. 5, p. 471-477, 2003.

GROELL, R. CT of the pericardium. In: SCHOEPF, U. J. (Ed.). CT of the heart - Principles and applications. New Jersey: Human Press, 2005. p. 145-154.

INTERNATIONAL COMMITTEE ON VETERINARY HISTOLOGICAL NOMENCLATURE. 1994. Nomina histological. 3. ed. Columbia: Editorial Committee Hannover, 166 p.

KLUWER, R. S. The pericardium. Massachusetts: Academic Publishers, 2003. 357 p.

KÖNIG, H. E.; LIEBICH, H. G. Veterinary anatomy of domestic mammals. London: Manson Publishing Ltd, 2007. 700 p.

NAKATANI, T.; SHINOHARA, H.; FUKUO, Y.; MORISAWA, S.; MATSUDA, T. Pericardium of rodents: pores connect the pericardial and pleural cavities. The Anatomical Record, Hoboken, v. 20, p. 132-137, 1988.

SPODICK, D. H. The normal and diseased pericardium: current concepts of pericardial physiology, diagnosis and treatment. Journal of the Amarican College of Cardiology, San Diego, v. 1, p. 240-251, 1983. 